Uşak Üniversitesi Sosyal Bilimler Dergisi

$2015,8 / 1$

\title{
Sinematografik İmge ve Gerçeklik
}

Oğuz ADANIR*

\section{Özet}

Son yüzyıl içinde yapılan araştırmalar bakış ya da görmenin yalnızca fizyolojik değil aynı zamanda zihinsel bir algılama sürecine boyun eğdiğini göstermiş̧tir. Fotoğrafik imge, gerçekliğin sadece bazı özelliklerini yansıtabilir, zihin geye kalan kısmını önceden sahip olduğu bilgiyle ya da ilişkilendirdikleriyle tamamlar. Zihinsel süreçten geçmeyen bir algılamadan bahsetmek imkânsızdır. İmge, hiçbir zaman, gerçek ya da gerçekliğin yerini alamaz, olsa olsa yansıtabildiği kadarıyla gerçek ya da gerçekliğin çok küçük bir bütününün imgesi olabilir. Sinematografik gerçeklik, kurmacadır ve kurmaca görüntüye gerçeklik kazandırmanın yolları; işitsel, görsel ve kurgusal bir takım düzenlemelerden geçmektedir. Bir diğer deyişle, film, kurmaca gerçeklik evreninin gerçekliğine seyirciyi inandırmaya çalışır. Sinematografik gerçekliğin somut gerçek evren ile ilişkisi nasıldır? Ya da somut olaylar filme nasıl dönüşür? Bu bağlamda, metin, imge ve gerçeklik ilişkisini film örnekleri üzerinden incelemektedir.

Anahtar Kelimeler: İmge, Gerçeklik, Sinematografik Gerçeklik.

\section{Cinematographic Image and Reality}

\begin{abstract}
Some researches conducted within the last century showed that perspective or vision conformed not only to physiological but also a mental perception process. Photographic image can only reflect some features of reality, mind completes the rest of that with the things which it associates or information which it already has formerly. It is impossible to mention a perception which doesn't pass through the mental process. Image cannot replace of the real or reality, at the most, it can be an image of a very small aggregate of the real or reality as far as it can reflect. Cinematographic reality is a fiction and the ways that give the reality to this fictional image get through the auditory, visual and fictional regulations. In other words, film tries to convince the audience to believe the reality of fictional reality space. How is the relationship between cinematographic reality and the concrete real space? Or how do the concrete occurrences turn into a film? In
\end{abstract}

* Prof. Dr., Dokuz Eylül Üniversitesi Güzel Sanatlar Fakültesi 
this context, this paper has analyzed the relation of image and reality through examples of films.

Key Words: Image, Reality, Cinematographic Reality.

\section{Giriş}

$\mathrm{Bu}$ başlık altında içinde yaşadığımız somut gerçeklik, canlılar ve nesnelerle onları yansıttıkları varsayılan imgeler arasındaki ilişkileri çözümlemeye çalışacak, istisnaları göz ardı edip, çoğunluğu kapsayan genellemelerle yetineceğiz.

Böyle bir konudan söz etmek algılamadan yani bakmaktan ve görmekten söz etmek demektir. Son yüzyıl içinde yapılan araştırmalar bakış ya da görmenin yalnızca fizyolojik değil aynı zamanda zihinsel bir algılama sürecine boyun eğdiğini göstermiştir. Örneğin, baktığımız fotoğraftaki otuzlu yaşlarda oldukları anlaşılan yan yana duran kadın ve erkek imgesi yalnızca bir imge değil anne ve baba imgesinin çağrıştırdığı tüm duygusal, düşünsel verilerle birlikte algıladığımız bir imgedir. Hiç bilmediğimiz, tanımadığımız nesnelerin, canlıların imgelerine baktığımız zaman bile bu bir bakıma pasif bir bakış değil, sorgulayıcı bir bakış olabilir; başka bir deyişle zihnimiz bakış anında aynı zamanda bu imgelerin hangi duygu ve düşünceleri yansıttığıyla ilgilenebilir. Bir yanıt bulamadığı zaman anında kendisi ilişkili, ilişkisiz yanıtlar üretebilir.

Sabit fotografik imge gerçekliği, nesneleri, varlıkları tüm özellikleriyle yansıtamaz. Onların yalnızca görece görsel niteliklerinin bazılarını sunabilir. İmge üstünde yer alan mekanlar, canlılar ya da nesnelerin renkleri, boyutları, ağırlıkları, kokuları, sesleri, hacimleri, vs konusunda yalnızca görüntülerine bakarak bilgilenebilmemiz olanaksızdır. $\mathrm{Bu}$ işi ancak o varlıklar konusunda daha önceden bir bilgiye sahip olmamız koşuluyla kişisel düş gücümüzü devreye sokarak gerçekleştirebiliriz, yani zihinsel bir süreçten geçmeyen bir algılamadan söz edebilmek neredeyse olanaksızdır.

Hatta sabit fotografik imge, ancak belli bir 1şık, belli bir pozlama ve uzaklık ayarıyla yansıması olduğu şeyle bir benzerlik kurulmasını sağlar. Burada imge, imgesi çekilen şey, kamera ve bakış arasındaki ilişkileri bizim bakış açımızdan şöyle betimleyebiliriz. İmgesi çekilen şeyin/nesnenin kendisini çekecek bir kameraya/özneye gereksinimi vardır. Bir imgenin imge olduğunun anlaşılabilmesi için izleyiciye/bakan kişiye ve izleyicinin de karşısında duran şeyin gerçeğin/gerçekliğin kendisi değil imgesi/hakikat olduğunu anlayabilmesi gerekmektedir. Başka bir deyişle imge hiçbir zaman gerçek ya da gerçekliğin yerini alamaz, olsa olsa yansıtabildiği kadarıyla 
gerçek ya da gerçekliğin çok küçük bir bölümünün imgesi olabilir. Örneğin, fotoğrafta yer alan kırklı yaşlardaki kişi hakkında yalnızca fiziksel özelliklerinden yola çıarak bir şeyler söyleyebiliriz. Dolayısıyla tekil düzeyde bile olsa imgenin yansıttığı şeye ait gerçekliğin ancak belli bir bölümünü sunabildiğini söyleyebiliriz.

Bu bir cansız madde ya da bir bitki olduğu zaman da fotoğraf daha ileriye gidememektedir. Bu durumda acaba sinemanın bu somut gerçeklik, canlı ve nesneleri yansitma konusunda daha avantajlı bir konuma sahip olduğu söylenebilir mi? Yalnızca görüntü düzeyinde kalındığında bu sorunun yanıtı büyük ölçüde hayır olmak durumundadır. Bir örnekle açıklamaya çalışalım. Gündelik yaşama ait bir aşk ya da bir hastalık, vs konu alan bir film düşünelim. Bu filmdeki ses şeridinin sesini tamamen keselim ve görüntüler üzerinden olan biteni kavramaya çalışalım. Öykü çok basitse bir takım doğru çıkarsamalarda bulunabilmek mümkündür, ancak görüntülerde birebir neler olup bittiğini açıklayabilmek olanaksızdır. Neden?

Çünkü somut gerçekliğin bir parçası olan ev ya da hastanenin gösterilmesi neler olup bittiğinin anlaşılmasını sağlayamamaktadır. Çünkü sinematografik gerçeklik bir kurmacadan ibaret olup, bu kurmacaya görüntüler dışında bir gerçeklik duygusu kazandırmanın yolu diyaloglar/sesler, müzik/melodi, gürültüler/zaman, mekan ve kişilerle ilişkili işitsel unsurlar, kurgu/dilyetisi/görüntülerin sıralanma mantığı ya da biçiminden geçmektedir. Christian Metz bu olayı "gerçeğe benzerlik", "gerçeklik izlenimi" gibi deyimlerle ifade etmektedir. Jean Mitry, Metz ve daha birçok kuramciya göre sinema gerçekliği yansitamaz. Zira sinemanın bir gerçeklikten söz edebilmesi için önce onu yaratması gerekir. Bu bir atmosfer sorunu olup, buna olsa olsa sinematografik gerçeklik evreni denilebilir.

Yönetmen belli bir yerde, belli bir zamanda, belli kişi ya da kişilerin başına gelen olaylardan söz edebilmek için sinematografik anlamda yani sinemanın teknik, estetik kurallarına ve aynı zamanda olayların geçtiği kurmaca gerçeklik evrenine ait mantıksal sürece ters düşmeyecek bir yol izlemek durumundadır. Başka bir deyişle yönetmen olağan koşullarda belli bir yerde, belli bir zamanda, belli kişiler arasında yaşanmış olayların birebir tanığı olsa bile bunları o gerçeklik evreninde yaşanan şekliyle ve o mekanlardan yararlanarak anlatamaz ya da aktaramaz. Bu olayların sinematografik anlatım mantığ 1 ya da sinematografik dilyetisine uygun bir hale getirilmesi gerekmektedir. Gerçeğe benzerlik ya da gerçeklik izleniminin kusursuz olabilmesi için gerek görüntüler gerek diyaloglar 
gerek oyunculuk gerek kurgu gerekse diğer unsurlar arasında kusursuz bir uyumluluk olması şarttır.

Başka bir deyişle öykülü film önce kendi gerçeklik evrenini oluşturup kendisini oluşturan tüm unsurlarla izleyiciyi yarattığ1 ya da oluşturduğu kurmaca gerçeklik evreninin gerçekliğine inandırmaya çalışır. Bir kez bu işi başardığında izleyici filmi hem tamamen düşsel hem de sanki gerçek yaşamda bir olaya tanık olurmuşçasına izler. Dolayısıyla gerçek yaşamda olan biten olaylar ve öykülerin onları yaşayan insanlar üzerinde bıraktığı etki ve izlerin benzerlerini seyirci üzerinde oluşturmanın yolu genellikle bunları yeni baştan tasarlamak ve gerçekleştirmek/filmleştirmekten geçmektedir. Zira kimi zaman akılcı düşünceye boyun eğen kimi zaman da boyun eğmeyen gündelik yaşamda olaylar bazen çok mantıklı bir silsile izlese de sinema seyircisi bu kadarı da olamaz diyebilmekte ve filmi gerçekçi bulmayabilmektedir. Olayların birebir yaşandığı biçimde gösterilmesini seyirci gerçekçilik adına yadsiyabilmektedir. $\mathrm{Bu}$ durumda geriye sinematografik gerçeklik seçeneğinden başka bir şey kalmamaktadır.

Peki sinematografik gerçekliğin somut gerçeklik evreniyle olan ilişkisi nasıl açıklanabilir? Bu son derece karmaşık bir süreçtir. Ancak elimizden geldiğince yalınlaştırarak açıklamaya çalışalım. Gündelik yaşama özgü bir tiyatro oyunundan yola çıkalım. Tiyatro oyununun oynanacağ sahnede teknik ekip ve oyuncular dışında oyunda belli bir önem ve işleve sahip eşyalar, nesneler vardır. Oyuncuların belli bir öyküleme mantığına boyun eğen oyuna fiziksel özellikleri, ses tonları, giysileri, birbirleri ve eşyalarla kurdukları ilişkiler, vs sonucu sahnedeki küçücük düşsel evrene bir gerçeklik duygusu kattıkları ya da katabildikleri ölçüde oyunun başarılı olabildiği söylenebilir. Tiyatroda mekan da, zaman da, oyuncular da somut bir şekilde izleyicinin karşısında durmakta ancak seyirci bir anlamda bütün bu somut varlıklarla düşsel bir evrende olan biten olaylara tanık olduğuna hem inanmakta hem de inanmamaktadır. Oyuncular ve seyirci arasında yakın bir duygusal ilişki kurulması durumunda düşsellik boyutu güçlenen ve izleyiciyi bulunduğu koltuktan alıp o sahne adlı küçücük evrende olan bitenlere odaklanmasını sağlayan tiyatro oyunu, bir yandan da seyirciye bir salonda olduğunu ve gerçeklikten tamamen kopmasının olanaksız olduğunu söylemektedir. Özetle oyun seyirciye bir tiyatro salonunda bulunduğunu unutturabildiği ölçüde başarılı sayılmakta, yani gerçek unsurlarla olabildiğince inandırıcı bir düşsel evren yaratılmaya çalışılmaktadır.

Aynı gündelik olay ya da bir benzeri öykülü bir sinema filmine nasıl dönüştürülmektedir? Görünüşe göre sinemanın işi daha kolaydır. Çünkü 
sinemada tiyatronun aksine bir bakıma tüm unsurlar düşseldir. Öykü ve olayların geçtiği mekanlar, kahramanlar, gerçeklik evreni tamamen düşseldir. Burada seyirci elini uzattığında yalnızca beyaz perde üzerindeki hayallere dokunabilmektedir. Peki nasıl oluyor da seyirci izlediği olaylar, kahramanlar ve görüntülerin etkisi altında kalıp bunları tıpkı gerçeklik evreninde tanık olduğu olaylar, kahramanlar şeklinde algılayabiliyor?

Algılama süreciyle ilgili karmaşayla tam da bu noktada karşılaşılmaktadır. Çünkü seyirci kesinlikle karşısında olmadığını bildiği bir gerçeklik evreninde kahramanların yaşadıkları olayların gerçekliğinden etkilenmektedir. Tiyatro oyununda olduğu gibi ortada bir sahne ve gerçek kişiler olmamasına karşın bu etkileme gücünün kökeninde ne vardır? Sahip olduğu teknik ve estetik özellikler gereği en gerçekçi öykülü film bile daha başlangıçta bir düşten ibaret olduğunu kabul etmek durumundadır, zira seyirci sinemada gerçeğin kendisini değil olsa olsa onunla asgari düzeyde ilişki kurmasını sağlayan görüntüler görmek istemektedir.

Biraz geriye gidip yola sessiz sinema filmlerine özgü imgeler ve gerçeklik ilişkisinden çıkalım. Bu sinemanın teknik yetersizlikleri içinde yaşanılan gerçeklik evrenine dair en gerçekçi imgelerin bile düşselleşmesine yol açmıştır. Başka bir deyişle siyah beyaz film şeritlerinin bu teknik özellikleri nedeniyle kendiliğinden denilebilecek bir şekilde somut gerçeklik evreni, somut canlılar ve varlıkları düşselleştirirken; genel anlamda sessiz filmlerdeki mekanlar, kişiler ve zamanın en alt düzeyde bir gerçeklik duygusu oluşturma konusunda bile çok zorlandıkları söylenebilir. İmgelerdeki 1şık ve netlik sorunu gerçekliğin yeniden üretiminde büyük sorunlara yol açarken, devasa boyutlara sahip yakın çekim insan yüzleri seyirciyi büyülemektedir. Bir bakıma sessiz sinemanın sahip olduğu tüm özelliklere bakılarak neredeyse tamamen düşsel bir sinema olduğu, o dönem seyircisininse sahip olduğu bilinç düzeyi, kültürel birikim ve algılama yeteneği ya da düzeyiyle bu düşselliğe tamamen boyun eğdiği söylenebilir. Sözcüğün gerçek anlamında gerçekçi özellikler taşıyan filmlerin görece seslirenkli sinemayla birlikte başladığı söylenebilir. Ancak başlangıçta siyah beyaz filmlere yakın bir algılama sürecine yol açan bu filmlerin de belki istisnalar hariç gerçekçi olmaktan çok düşsel öykülere benzedikleri söylenebilir. Ancak 1960'lar, 1970'lerden sonra gerçekçi sinema örneklerinde bir artış olduğu söylenebilir.

Günümüze doğru gelindiğinde içinde yaşanılan somut gerçeklik evreni, canlılar, nesnelerden yararlanılarak çekilen gerçek yaşama dair öyküler nasıl algılanmaktadır? Yukarıda da söylediğimiz gibi içinde yaşanılan gerçekliğin ve gerçek öykülerin oldukları, yaşandıkları şekilde 
anlatılmaları, aktarılmaları mümkün değilse o zaman neler olup bitmektedir?

Her şeyden önce öykülü sinemanın bir gerçeklik atmosferi, gerçeklik duygusu yaratması gerektiğini söyledik. Sinemanın ve seyircinin yıllar boyunca edindiği deneyim uzun bir süreden bu yana herhangi bir konu ya da öyküyle ilgili gerçekçi bir atmosfer oluşturulmasını, yaratılmasını kolaylaştırmaktadır. Kısaca bunun kökeninde deneyim vardır. Yeni filmler artık konu ve öykülerine göre daha önce gerçekleştirilmiş başarılı filmlerdeki atmosferleri örnek alarak kendilerine en uygun gerçekçi görüntüleri oluşturabilmektedirler. Sinemada gerçeklik, gerçekçilik denildiğinde bambaşka şeyler anlaşılması gerektiği ortadadır. Bir kez gerçeklik tanımı yapılabilen bir şey değildir, başka bir şekilde söylemek gerekirse gerçekliğin toplumsal, politik, kültürel, ekonomik, dini, ahlaki, hukuki, felsefi vs tanımları olup, gerçeklik zaman içinde sürekli değişebilen bir kavramdır. Dolayısıyla bir öykünün belli bir döneme ve mekana ait belli kişilerle gerçekleştirilmesi ait olduğu gerçeklik evrenini olduğu gibi yansıtması anlamına gelemez. Bu öykü o gerçeklik evreninin olsa olsa çok küçük bir bölümünü sunabilir. $\mathrm{O}$ yüzden bu öyküye bakarak o gerçeklik evreninin tümü hakkında bir çıkarsamada bulunulamaz, olsa olsa gösterilen bölümüyle ilgili bir şeyler söylenebilir. Peki ama öykülü film gerçekliği değiştirip, dönüştürmeden sunamıorsa filmden yola çıkılarak sunduğu varsayılan gerçeklik konusunda nasıl fikir üretilebilir? Bu durumda filmin neyi ne kadar değiştirdiğinin bilinmesi gerekir ki, bu mümkün değildir, hatta olayları bizzat yaşamış bir yazarın, bir yönetmenin bile sözünü ettiği gerçekliğin tümünü yansıtabilmekten çok uzak oldukları söylenebilir. Aynı gerçeklik evreni değişik bakış açılarından sunulduğunda farklı bir şekilde kavranabiliyorsa o zaman ortada ya gerçeklik diye bir şey bulunmadığ ya da gerçekliğin belli ilkeler çerçevesinde algılanması gerektiği anlaşılır. Bu ilkelere örnek vermek gerekirse aynı gerçekliğin solcu bir bakış açısından başka, sağcı bir bakış açısından başka bir şekilde algılandığı söylenebilir. Toplum ya da seyircinin bu bakış açılarını benimsemesi durumunda gerçeklikle ilgili en fazla iki ya da üç egemen bakış açısının varlığından söz edilebilir. İnsanlar benimsedikleri bakış açısı çerçevesinde algıladıkları gerçekliğe uymayan gerçekçi öyküleri karşıt ya da başka bakış açısına uygun bir gerçeklik olarak nitelendirdiklerinden gerçeklik evreni ya da gerçekliğin somut bir şekilde sunulma şansının olmadığı söylenebilir.

Gerçekçi filmler içinde yaşanılan gerçekliği ancak belli bir ilkeye uygun bir şekilde sunabiliyor ve bu işi ancak sinemaya uygun bir şekilde değiştirip dönüştürerek yapabiliyorlarsa seyirci gerçekçi bir filmde gerçekliğe dair ne görebilmekte ya da algılayabilmektedir? Gerçekçi bir 
filmin ait olduğu varsayılan gerçeklik evreninden alıp kullanabildiği imgeler o ilk evrenle olan ilişkilerini tamamen kopartarak filmsel gerçeklik evreninin hesabına geçirilmektedirler. Başka bir deyişle gerçeklik evreninin derisi olarak kabul edilebilecek dışsal görünüm kamera tarafından soyulup alınarak film adlı evrene yapıştırılmakta ve onun bir parçası haline gelmektedir.

Sonuç olarak bu bağlamda sinema demek illüzyondan söz etmek demektir. Ancak burada sözü edilen şey gerçeklik olup bu gerçeklik istese de istemese de bir masal, bir illüzyon gibi sunulmak durumundadir. Buradaki gerçeklik tüm gerçekliğini yitirip, masala, öyküye dönüştürülmüş bir gerçekliktir. Böyle bir filmde seyirciyi duygulandıran, etkileyen bir şeyler varsa bunun sinematografik gerçekliğe ait olan unsurlar, özelliklerden kaynaklandığı söylenebilir. Dolayısıyla gerek dünya sineması gerekse yerli sinemamızda gerçeklikle ilgili gerçekçi filmlerin varlıklarını "yeniden oluşturulan sinematografik bir gerçeğe benzerliğe" borçlu olduklarını ve sözcügün gerçek anlaminda gerçekçi filmlerden söz etmenin mümkün olamayacağını söyleyebiliriz. Çok uzun bir süreden bu yana bilindiği üzere gerçek/gerçeklik öykü anlatmaz ama sinema anlatır. Sinema bağlamında sinema tarafından öyküleştirilemeyen bir gerçek/gerçekliğin sinema seyircisine ulaşma şansı yoktur. 
O. ADANIR 8 